\title{
Neuromorphology and Neuropharmacology of the Human Penis
}

\author{
AN IN VITRO STUDY
}

\author{
George S. Benson, JoAnn MCCONNEll, LARRY I. Lipshultz, \\ JoSEPH N. CoRriere, JR., and JoE WoOD, Division of Urology, Department of \\ Surgery and Department of Neurobiology and Anatomy, The University of Texas \\ Medical School at Houston, Houston, Texas 77030
}

\begin{abstract}
A B S T RACT The neuromorphology and neuropharmacology of the human penis are only briefly described in literature. The present study was undertaken to define the adrenergic and cholinergic neuromorphology of the human corpus cavernosum (CC) and corpus spongiosum and to evaluate the in vitro response of the $\mathrm{CC}$ to pharmacologic stimulation. Human penile tissue was obtained from six transsexual patients undergoing penectomy. For morphologic study, the tissue was processed for $(a)$ hematoxylin and eosin staining; $(b)$ smooth muscle staining; $(c)$ acetylcholinesterase localization; $(d)$ glyoxylic acid histofluorescence; $(e)$ electron microscopy; and $(f)$ electron microscopy after glutaraldehyde dichromate fixation. In addition, strips of CC were placed in in vitro muscle chambers and tension changes recorded isometrically after stimulation with norepinephrine (NE) and acetylcholine. The CC contains abundant smooth muscle, numerous glyoxylic acidfluorescent (catecholaminergic) fibers and varicosities, and a scant distribution of acetylcholinesterase-positive fibers. Fewer of all these elements were present in the corpus spongiosum. No "polsters" were observed in the CC. Although glutaraldehyde-fixed controls exhibited no typical adrenergic vesicles (small, dense core, measuring 400-600 $\AA$ in diameter), some small, strongly electron-dense vesicles were found in glutaraldehyde dichromate-fixed tissue and were thought to contain NE. A variety of other vesicles were also encountered. The addition of $\mathrm{NE}$ to the in vitro muscle chambers caused a dose-related contraction, which was
\end{abstract}

Dr. Benson is the recipient of Research Scholarship (19771979) from the American Urological Association, Inc. Dr. McConnell is the recipient of National Institutes of Health National Research Service Award 1-F32 NS06179-01 (19791981). Address reprint requests to Dr. Benson.

Received for publication 12 March 1979 and in revised form 22 October 1979. blocked by pretreatment with phentolamine in all CC strips tested. Acetylcholine in high concentration produced minimal contraction in 2 of 24 strips. Our morphologic and pharmacologic data suggest that the sympathetic nervous system may affect erection by acting not only on the penile vasculature but also by direct action on the smooth muscle of the CC itself.

\section{INTRODUCTION}

The human penis has been the subject of little morphologic or physiologic investigation since Conti's description of "polsters" in 1952 (1). The neuromorphology of this organ in the adult has been only briefly described (2). Furthermore, most theories that have been proposed to explain the mechanism of penile erection and detumescence have dealt with changes in the vascular supply of the penis but have not considered an active role for the cavernous bodies of the penis inself. The present study was undertaken $(a)$ to define the neuroanatomy of the human penis on both light and electron microscopic levels, and $(b)$ to determine the in vitro response of the human corpus cavernosum to neuropharmacologic stimulation.

\section{METHODS}

Penile tissue was obtained from six male transsexuals undergoing gender reassignment operations. The patients' ages ranged from 24 to $35 \mathrm{yr}$ and all had been treated with ethinyl estradiol $(1 \mathrm{mg} / \mathrm{d})$ for $\sim 1 \mathrm{yr}$ before the operative procedure. All patients underwent penectomy, bilateral orchiectomy, and creation of a neovagina using penile skin. That portion of the penis between the decussation of the crura proximally and the glans penis distally was used for the present study.

\section{Morphology}

Light microscopy. Immediately after resection, the penile tissue was either frozen at $-20^{\circ} \mathrm{C}$ or fixed in $10 \%$ formalin. 
Frozen sections, cut at $20 \mu \mathrm{m}$ were used for the glyoxylic acid (GA) ${ }^{1}$ histofluorescence method (3), for acetylcholinesterase (AChE) localization (4), and for hematoxylin and eosin staining. Histofluorescence was examined with a Zeiss photomicroscope having filter combination 48-77-03 (A BT 405/8 excitation filter and an LP 418 barrier filter; Carl Zeiss, Inc., New York). Formalin-fixed, paraffin-embedded material cut at 10-12 $\mu \mathrm{m}$ was stained with hematoxylin and eosin or either phosphotungstic acid-hematoxylin or Levanol fast cyanin 5 RN (5) for specific staining of smooth muscle cells.

Electron microscopy. Small pieces of human corpus cavernosum and corpus spongiosum were fixed immediately after resection in $4 \%$ glutaraldehyde (with $1 \%$ sodium molybdate in $0.2 \mathrm{M}$ cacodylate buffer at $\mathrm{pH} 7.2$ ). Half of the tissue was further treated with glutaraldehyde-dichromate (G-DC), which allows for specific identification and localization of catecholamines (6), and the remaining half served as the control material. Dehydration was accomplished in 3,3-dimethoxypropane to decrease the loss of dichromate deposits which often occurs in graded alcohols (7). Tissue sections were examined in detail to characterize the tissue as a whole, but with particular attention to the nerve fibers and varicosities. G-DC tissue was examined for electron-dense deposits of chrome, which binds only to norepinephrine or dopamine under the specific conditions employed ( $4 \%$ glutaraldehyde with $2 \%$ sodium sulfate and $2.5 \%$ potassium dichromate in $0.2 \mathrm{M}$ cacodylate buffer at $\mathrm{pH} 4.1$ ).

\section{In vitro muscle bath}

Four strips of tissue from the corpus cavernosum of each patient were studied. The strips (measuring $\sim 1.0 \times 0.4 \mathrm{~cm}$ ) were placed in muscle chambers containing Tyrode's solution ( $125.0 \mathrm{mM}$ sodium chloride, $2.7 \mathrm{mM}$ potassium chloride, 0.4 $\mathrm{mM}$ sodium dihydrogen phosphate, $1.8 \mathrm{mM}$ calcium chloride, $0.5 \mathrm{mM}$ magnesium chloride $6 \mathrm{H}_{2} \mathrm{O}, 23.8 \mathrm{mM}$ sodium bicarbonate, and $0.2 \%$ dextrose) buffered to $\mathrm{pH} 7.50$ with concentrated hydrochloric acid at $37^{\circ} \mathrm{C}$ and perfused with a gas mixture of $95 \%$ oxygen and $5 \%$ carbon dioxide. The strips were allowed to equilibrate for $0.5 \mathrm{~h}$ at a tension of $\sim 1 \mathrm{~g}$. The contractile response of each corporal strip to pharmacologic stimulation was recorded isometrically with a Grass FT-03 force transducer (Grass Instrument Co., Quincy, Mass.) connected to a Beckman recorder (Beckman Instruments Inc., Fullerton, Calif.).

After equilibration, the strips were stimulated with levarterenol bitartrate (norepinephrine) $(0.6-60 \mu \mathrm{M})$ before and after pretreatment for $5 \mathrm{~min}$ with phentolamine mesylate $(40 \mu \mathrm{M})$ or propranolol hydrochloride $(40 \mu \mathrm{M})$. The effect of acetylcholine chloride ( 5 to $50 \mu \mathrm{M}$ ) before and after pretreatment with atropine sulfate $(40 \mu \mathrm{M})$ was also recorded.

\section{RESULTS \\ Morphology \\ LIGHT MICROSCOPY}

Hematoxylin and eosin and smooth muscle stains. Examination of human erectile tissue stained by these methods shows the histology typically described in textbooks for the corpus cavernosum (CC) and corpus

\footnotetext{
${ }^{1}$ Abbreviations used in this paper: AChE, acetylcholinesterase; CC, corpus cavernosum; CS, corpus spongiosum; EM, electron microscopy(ic); GA, glyoxylic acid; G-DC, glutaraldehyde-dichromate.
}

spongiosum (CS). Both regions demonstrate numerous cavernous spaces partitioned by trabeculae containing bundles of collagen, elastic fibers, fibroblasts, and groups of smooth muscle cells. However, the CS has smaller trabeculae with few smooth muscle cells and, in general, larger vein-like, cavernous spaces. Although the cavernous bodies contain numerous arterioles, none of these demonstrate polsters, columns of smooth muscle cells protruding into the lumen in the fashion described by von Ebner (8) and Conti (1) as "von Ebner pads" or polsters, respectively. A few such structures were found in the CS but are located in veins or small cavernous spaces.

AChE localization. AChE-positive fibers appear in limited numbers in the human CC and CS. The CC consistently shows a scant distribution of these structures, whereas they are sparse or even lacking in the CS. The fibers are often organized in small bundles that sometimes course near arterioles (Fig. 1). Most arterioles are approached by individual AChE-positive fibers and frequently demonstrate AChE-positive structures thought to be cholinergic terminals in their outer tunic (Fig. 1).

Histofluorescence. GA-fluorescent fibers and terminals, indicative of catecholaminergic elements, are found in varying amounts in all samples of $C C$ and $C S$ examined. The CC contains numerous GA-fluorescent fibers, which take a circuitous course through the trabeculae and often appear to approach the walls of the cavernous spaces (Figs. 2 and 3). The CS contains very few histofluorescent fibers, but autofluorescent elastic fibers occur more frequently (Fig. 4). The dull yellow-green color and smooth outline of autofluorescent fibers (collagen, elastin) is easily distinguished from the brilliant blue-green of the varicose GA-fluo-

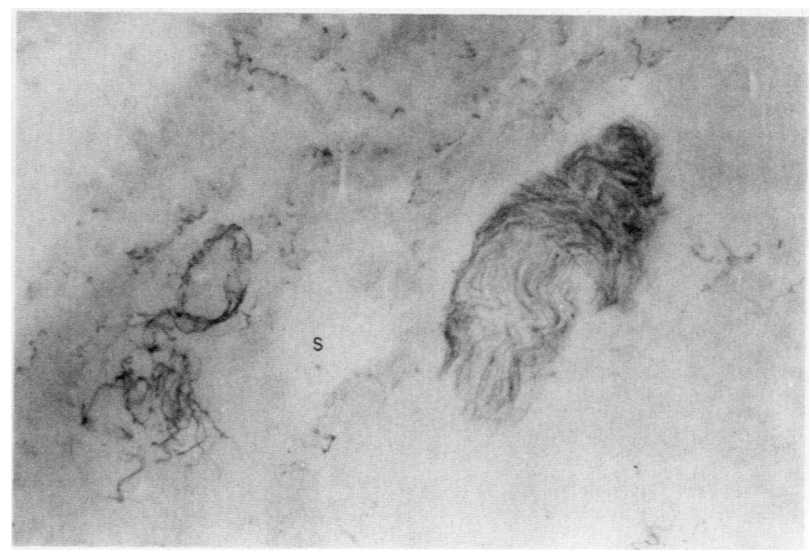

FIGURE 1 Photomicrograph of a frozen section of human CC treated for AChE localization. AChE-positive nerve fibers are shown in the bundle on the right, in the wall of an arteriole at the left, and scattered in the surrounding tissue. A small cavernous space is located near the center of the photo $(S) . \times 20$. 


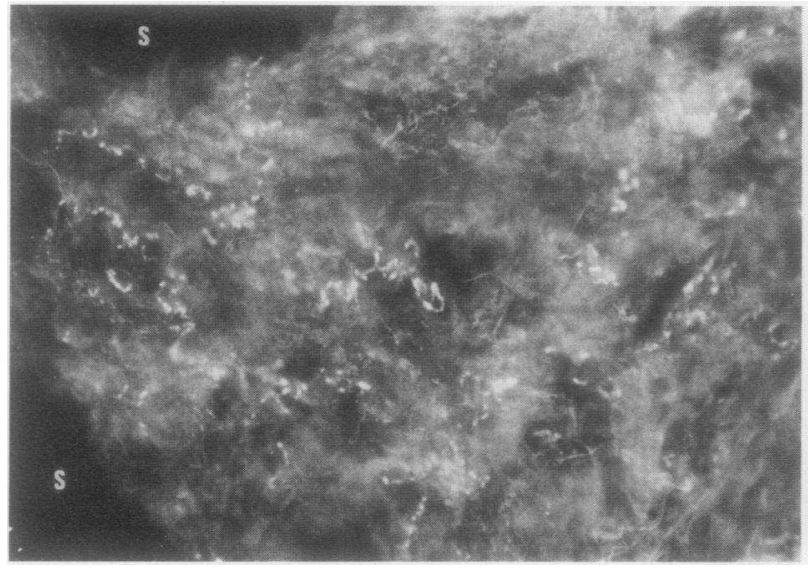

FIGURE 2 Fluorescence photomicrograph of a GA-treated frozen section of human CC. Numerous GA-fluorescent fibers can be seen following a tortuous course through the tissue. The neon-bright and varicose adrenergic fibers are easily distinguished from the dimmer and smoother autofluorescent connective tissue fibers. Two large cavernous spaces are shown on the left $(\mathrm{S}) . \times 22$.

rescent fibers. Many, but not all blood vessels, demonstrate adrenergic varicosities in the outer tunic.

\section{ELECTRON MICROSCOPY (EM)}

Ultrastructural examination of human erectile tissue reveals numerous irregularly shaped cavernous spaces separated by trabeculae. The dimensions, orientation, and components of the trabeculae in the CC vary considerably. Their surfaces, the walls of the cavernous spaces, are covered by endothelial cells such as those found in blood vessels, but they contain varying con-

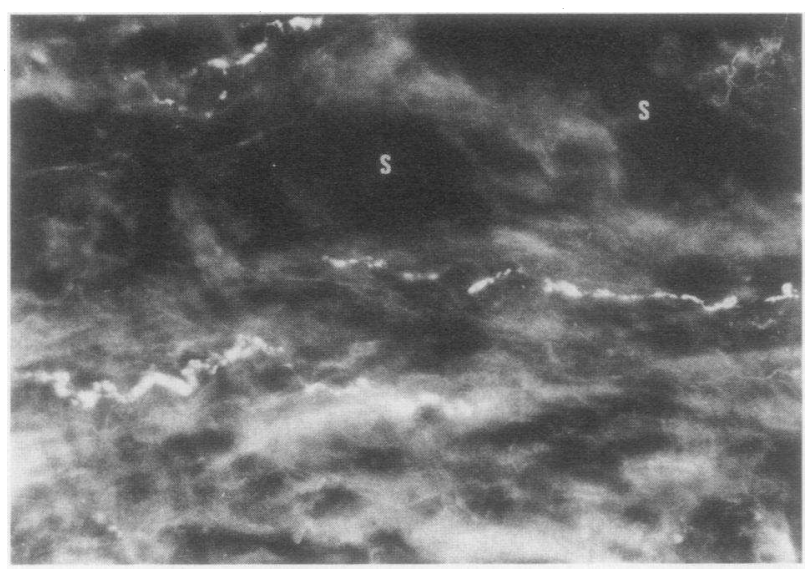

FIGURE 3 Fluorescence photomicrograph of a GA-treated frozen section of human CC. At this higher power (than in Fig. 2), the numerous varicosities of the brilliant GA-fluorescent fibers (center and above left) show up clearly against the background autofluorescence. Cavernous spaces appear above, in the center and to the right $(S) . \times 36$.

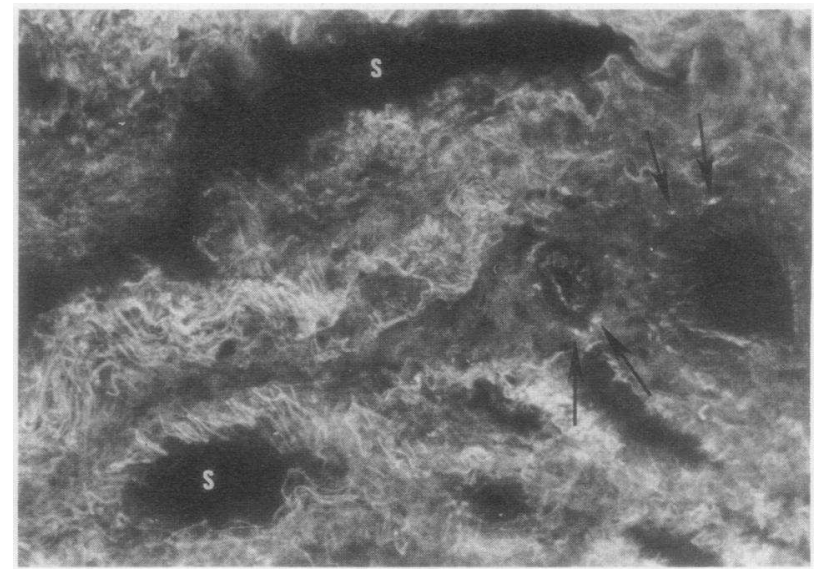

FIGURE 4 Fluorescence photomicrograph of a GA-treated frozen section of human CS. A few small blood vessels at right. Most notable, however, is the extensive autofluorescent connective tissue (collagen and elastic fibers) running through the trabeculae and surrounding the blood vessels and veinlike cavernous spaces (S). Note the differences between this figure and that of human CC in Fig. 2. Despite the slight variation in magnification, it is clear that the $C C$ contains more abundant GA-fluorescent fibers, less dense connective tissue, and larger trabeculae. $\times 20$.

centrations of smooth muscle, fibroblasts, elastic fibers, collagen, capillaries, and neural elements. Smooth muscle cells have "ruffled" edges and usually occur in small groups, often with close contacts between the cells. Occasionally a single smooth muscle cell is found surrounded by connective tissue elements. The CS is composed of many narrow trabeculae containing abundant collagen and elastic tissue but very few smooth muscle cells and nerve fibers.

Despite extensive examination at the EM level, few single fibers or nerve terminals have been demonstrated. Most of the neural elements are profiles of small unmyelinated nerve bundles containing two to six fibers and/or varicosities. Vesicles within these varicosities are diverse in both glutaraldehyde and G-DC-fixed material. Most are small opaque and granular vesicles measuring 400-600 $\AA$ in diameter that do not have an electronlucent halo at the periphery (Fig. 5). Contained within the same varicosities or sometimes found alone in large cigar-shaped varicosities are large granular and opaque vesicles measuring $600-1,800 \AA$ in diameter. Those found in conjunction with small vesicles tend to be spherical and to have an electronlucent halo (Fig. 5), whereas those found independently sometimes lack a halo and are elongated (Fig. 6). Large clear vesicles $600-900 \AA$ in diameter are also seen occasionally. In addition, tissue fixed in G-DC demonstrates some small, highly electron-dense vesicles (Fig. 7), which are considered to be chrome-positive and, therefore, to contain norepinephrine (as dopamine has not been found in significant amounts in this part of the 


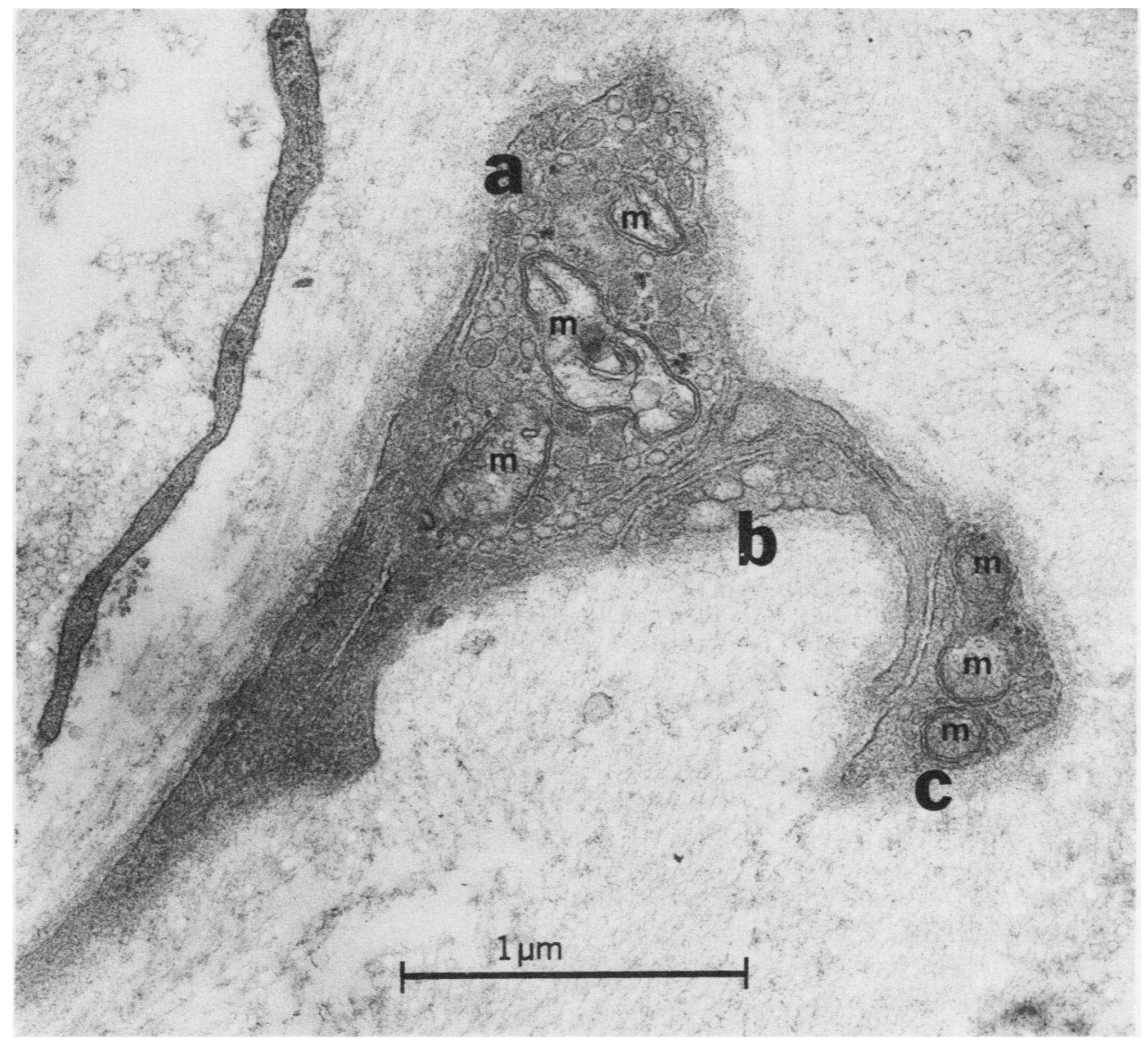

FIGURE 5 Electron micrograph of glutaraldehyde-fixed human CC (osmium postfix and lead stain). In addition to several mitochondria $(\mathrm{m})$, the largest varicosity (a) contains numerous small opaque vesicles and several large granular vesicles with a halo. Two smaller varicosities appear on the right $(b, c)$. One (b) contains small and large opaque vesicles, whereas the other (c) has a few opaque vesicles and three small mitochondria $(\mathrm{m}) . \times 36,000$.

peripheral nervous system). Many of the small opaque or granular vesicles appear similar in both the glutaraldehyde and G-DC treated material, however, and do not have the typical appearance of adrenergic vesicles. Small clear vesicles were not seen in either glutaraldehyde or G-DC fixed tissue, and no typical cholinergic varicosities were seen. The large clear vesicles may well belong to sensory processes, whereas varicosities with large opaque vesicles fit the descriptions for purinergic or peptidergic nerve fibers (9).

Varicosities of nerve fibers are generally 3,000-10,000 $\AA$ away from smooth muscle cells and often are found embedded in collagen with only a few closer than 2,000 $\AA$. The few myelinated nerve fibers observed are quite large $(5-10 \mu \mathrm{m})$.

\section{In vitro muscle bath}

None of the 24 strips of CC demonstrated spontaneous activity. The addition of norepinephrine to the chambers caused a dose-related contraction (threshold concentration of $0.6 \mu \mathrm{M}$ ) in all strips tested (Fig. 8). All norepinephrine-induced contractions were blocked by pretreatment with phentolamine and were unaffected by propranolol. Acetylcholine stimulation in high concentration produced a minimal contraction in 2 of 24 strips. This contraction was blocked by pretreatment with atropine.

\section{DISCUSSION}

The polster theory of erection and the primary importance of the parasympathetic nervous system in the control of erection have been generally accepted for so long that other possible mechanisms have not been explored. Conti (1), using cadaver material, demonstrated numerous longitudinally arranged columns of smooth muscle cells within the intima of the major arteries and veins of the penis including the helicine arteries. Based on this morphological evidence, he 


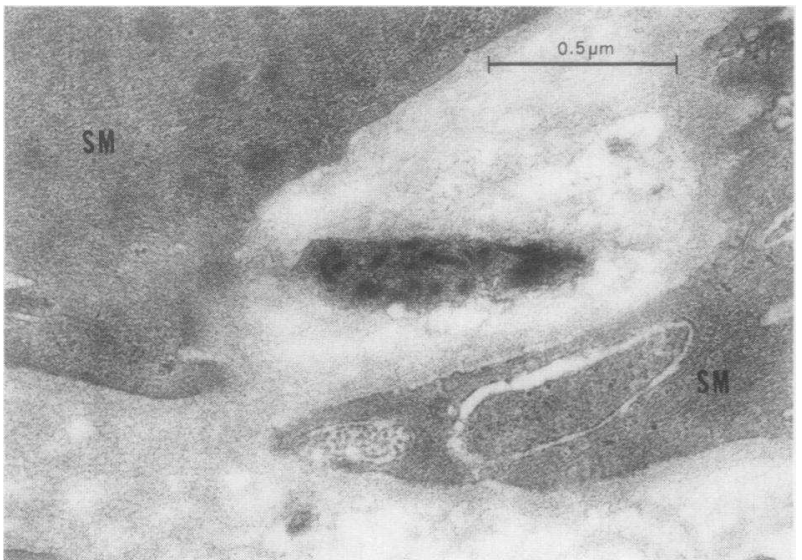

Figure 6 Electron micrograph of G-DC-fixed human CC (osmium postfix and lead stain). The varicosity between two smooth muscle cells (SM) demonstrates the large oblate vesicles with and without a halo, which are frequently seen in this tissue. This is considered to be a functional synapse because the varicosity is only about $2000 \AA$ from the adjacent smooth muscle cells (SM). The dark vesicles are not considered to be chrome-positive and their content is unknown at this time. They may well be peptidergic or purinergic. $\times 18,000$.

proposed that polsters control the flow of blood to the cavernous spaces of the corpora and thereby control erection and detumescence. In the present study, we were unable to find any evidence of muscular columns in the arteries of the CC and found only a few such structures in small veins or cavernous spaces of the CS. Leeson and Leeson (10) were also unable to find polsters in the CC of the rat.

Similar structures were first seen in the intima of blood vessels of other viscera nearly a century ago (11) and their significance has since been the subject of many debates. Borst and Enderlen (12), studying wound healing in blood vessels, found within $1 \mathrm{~d}$ after repair of a cut vessel that endothelial cells would proliferate and orient themselves with their long axis parallel to the axis of the vessel. After a few more days, many of these intimal cells assumed the appearance of smooth muscle cells. They concluded that these myoendothelial cells did not arise from the tunica media because the healing there occurred only by formation of collagenous scar. Recent EM studies have shown that these cells are smooth muscle $(13,14)$ and that they also appear in the intima of the aorta after fabric grafts (15) and in the blood vessels of patients with arteriosclerosis (16). Whether these myoendothelial bundles within the penile blood vessels are normal structures involved in the control of blood flow or are pathological evidence of vascular degeneration cannot be determined at this time.

Ruzbarsky and Michal (17) recently studied the morphological changes seen with aging in the intima of

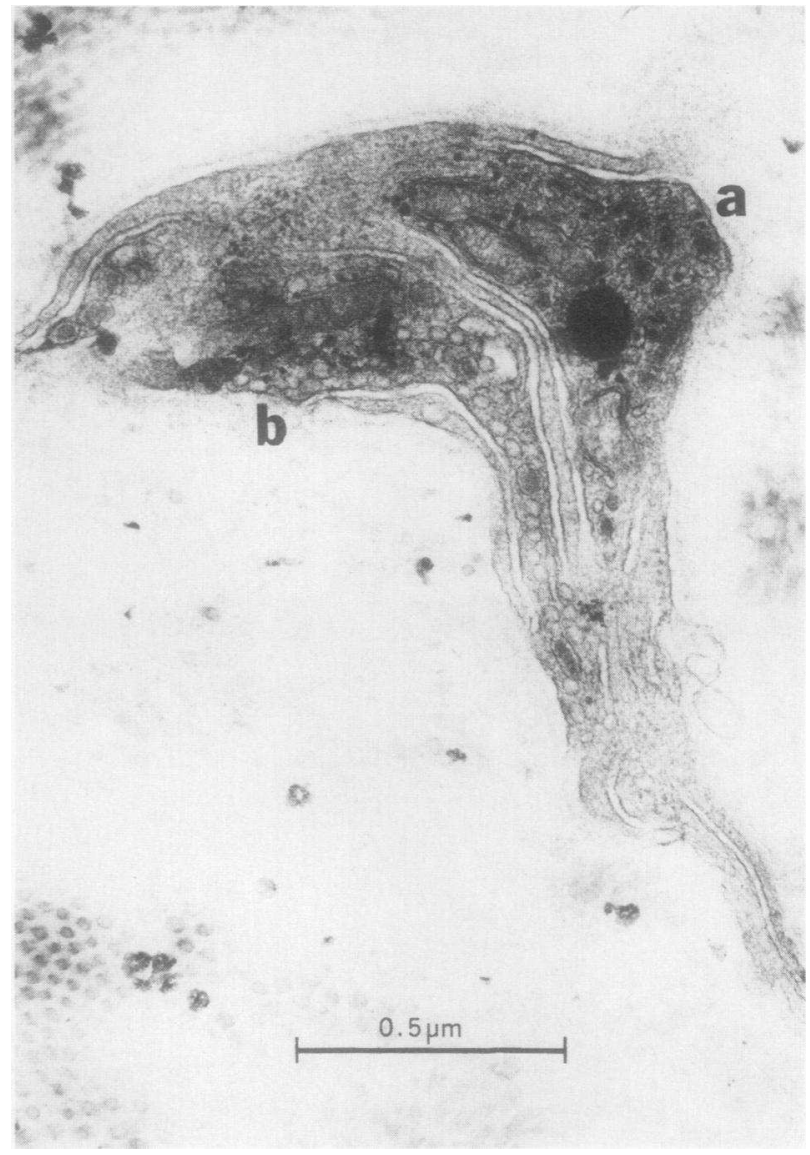

Figure 7 Electron micrograph of G-DC-fixed human CC (osmium postfix and lead stain). Two varicosities can be seen (a, b). One contains primarily small granular vesicles with electron-dense cores (a) and the other has many small opaque vesicles (b). A few larger, less dense granular vesicles with a halo at the periphery can be seen on the left and in the lower part of $b . \times 36,000$.

penile arteries (including the polsters) in cadaver material from control and diabetic individuals 19-85 yr of age. Most commonly seen was fibrosis of the polsters, a "replacement" of longitudinal muscle with collagenous connective tissue. Calcification of the fibrotic polsters was observed in some controls over age 60 and in all
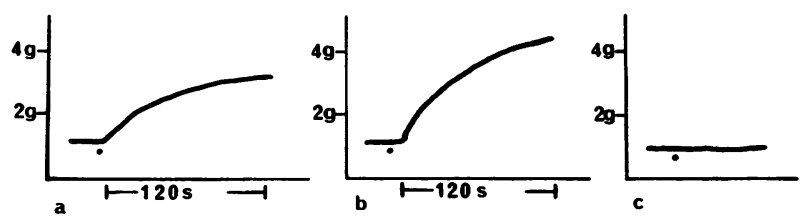

FIGURE 8 In vitro response of strips of corpus cavernosum to pharmacologic stimulation. (a) Contractile response to norepinephrine $(6 \mu \mathrm{M})$. (b) Contractile response to norepinephrine $(60 \mu \mathrm{M})$. (c) Addition of norepinephrine $(60 \mu \mathrm{M})$ after pretreatment of strip for $5 \mathrm{~min}$ with phentolamine mesylate $(40 \mu \mathrm{M})$. 
the diabetics over $54 \mathrm{yr}$ of age. These changes could be interpreted simply as the next steps in a disease process that began $v$. :th the production of myoendothelial cells. Conti (1) discusses the concept that the muscular columns have been proposed to appear with age and to aid decreased contractility, but because he found them in material from very youthful individuals, he felt it was not unreasonable to suggest that they had a normal function in directing regional blood flow. Recent research, however, has demonstrated that the first signs of arteriosclerosis can appear during the early teens and it is not inconceivable that it would appear even earlier in some cases.

In preliminary work, we have observed "polster-like" structures in penile tissue obtained from elderly cadavers. The absence of polsters in our transsexual material could be a reflection either of our examining a younger population or a population that had received long-term treatment with estrogen. The hormonal treatment given our patients would most probably increase myoendothelial proliferation, if anything, because this phenomenon has been reported in women taking birth control pills (18). If polsters, however, simply represent arteriosclerotic changes, their presence in elderly cadavers and absence in our material is not surprising. The only polster-like structure seen in our material was in the CS, which is not influential in bringing about erection. Although we cannot completely rule out the possibility that the hormone therapy altered the normal morphology in the tissue examined in the present study, we propose that the muscular columns as described by Conti are not functionally significant in the human.

The human CC in our material is well supplied with adrenergic nerve fibers but has few cholinesterasepositive fibers. This is in contrast to the results of Shirai et al. (2) wherein numerous cholinergic but few adrenergic nerves were seen (with the same AChE technique and freeze-dry histofluorescence) in human penile tissue obtained by penectomy for cancer. We feel that our results and techniques are confirmed by the favorable comparison to our previous work in the monkey and cat (19). The structures (presumably nerve fibers) containing AChE are widely dispersed in the tissue but are most often found in relation to blood vessels. That these AChE-positive fibers are cholinergic cannot be stated with any certainty. In some organs, such as the ovary, most of the AChE is localized in fibers shown to be adrenergic with the histofluorescent technique (20). Most penile blood vessels have AChEpositive structures and also demonstrate histofluorescent, adrenergic varicosities at their periphery. The majority of the adrenergic fibers, however, are distributed throughout the trabeculae of the $\mathrm{CC}$ in relation to the bundles of smooth muscle so that the varicosities appear to innervate the corporal musculature. Although no adrenergic synaptic contacts could be found with EM, many varicosities were close enough to smooth muscle cells to be considered "functional" synapses $(<5,000 \AA$ away).

The fine structure of the human penis is similar to that reported for the rat (10), although there are more numerous cavernous spaces and few myelinated nerves in the human corpora. Within the many small unmyelinated nerve bundles are varicosities which contain a wide variety of vesicles. Those appearing most often in the controls are slightly granular or opaque vesicles measuring 400-600 $\AA$ in diameter. However, these do not fit the established description for any particular nerve type. Adrenergic vesicles have been described as small (400-600 $\AA$ in diameter) with an electron-dense or granular core and a peripheral halo. Cholinergic vesicles are said to be small (400-600 $\AA$ in diameter) and clear or translucent because this is the type found at the neuromuscular junction. Unfortunately, these characteristics have been shown to vary with different fixatives and with variations in the $\mathrm{pH}$. Nevertheless, none of the varicosities resemble those belonging to known cholinergic nerves and many contain strongly electron dense, chrome-positive vesicles in the G-DC material, which indicates that they contain norepinephrine. Because no other vesicle type is seen with such frequency and considering the profuse GA-fluorescence and the scant $\mathrm{AChE}$, it appears that these opaque vesicles belong to varicosities of adrenergic nerves. The lack of the "typical" dense core may be related to the hormone treatment or other factors such as the anesthesia given to the patients (which has been shown to cause depletion of norepinephrine).

The large (800-2,000 $\AA$ ) granular or opaque vesicles seen frequently in our material are similar to those found in abdominal viscera (21) and those shown by Pickel et al. $(22,23)$ to be substance P-positive in the central nervous system. Burnstock $(9,24)$, however, has proposed that these large noncholinergic and nonadrenergic vesicles contain ATP as a neurotransmitter although this theory is difficult to prove because ATP is ubiquitous. Baumgarten et al. (21) saw similar vesicles in myenteric ganglia and called them "p-type" nerves because of their similarity to polypeptide-storing neurosecretory vesicles in the hypothalamus. Radioimmunoassay (25) and light microscopic immunohistochemistry $(26,27)$ have already demonstrated substance $\mathbf{P}$ in high concentrations in nerve fibers of the intestine and the genitourinary tract. Because substance $\mathrm{P}$ is one of the most potent agents known for smooth muscle contraction and vasodilatation (28), its presence in the human CC may be extremely significant. The present EM analysis of the human CC does not help to clarify the physiological role of the corporal smooth muscle since the orientation of the muscle bundles still appears to be random at the EM level. 
Serial section reconstruction of the trabeculae and cavernous spaces will probably be required before this organization is completely understood.

Our in vitro muscle bath results closely parallel those obtained by Klinge and Sjöstrand (29) in other species. The predominant response to pharmacologic stimulation is an alpha receptor mediated contraction; cholinergic stimulation, even at high concentrations, rarely results in a change in base-line tension. All of our patients were treated with long-term oral estrogen, and the effect of this therapy on the muscle bath results cannot be evaluated by the present data. Hormonal manipulation has been reported to alter the in vivo and in vitro response of other tissues to adrenergic stimulation $(30-33)$. The responses obtained in the estrogentreated humans are qualitatively identical, however, to those seen in nonhormonally treated monkeys (19).

The smooth muscle of the CC contains numerous adrenergic nerves and responds to norepinephrine stimulation in vitro with an alpha receptor-mediated contraction. This morphologic and pharmacologic data is consistent with a significant adrenergic innervation of the smooth muscle of the CC. In light of these findings, the penile CC cannot be considered simply as a passive reservoir for increased blood flow during erection. Active neurological, particularly sympathetic, processes may be important in the control of erection and detumescence. Impotence secondary to sympatholytic drugs and sympathectomy (34-36) may not be caused solely by vascular effects but also by neurological dysfunction of the CC itself.

\section{REFERENCES}

1. Conti, G. 1952. L'erection du penis human et ses bases morphologicovasculaires. Acta Anat. 14: 217-262.

2. Shirai, M., K. Sasaki, and A. Rikimaru. 1972. Histochemical investigation on the distribution of adrenergic and cholinergic nerves in the human penis. Tohoku J. Exp. Med. 107: 403-404.

3. de la Torre, J. C., and J. W. Surgeon. 1976. A methodological approach to rapid and sensitive monoamine histofluorescence using a modified glyoxylic acid technique: the SPG method. Histochemistry. 49: 81-93.

4. Karnovsky, M. J., and L. Roots. 1964. A "direct-coloring" thiocholine method for cholinesterases. J. Histochem. Cytochem. 12: 219-221.

5. Puchtler, H., F. Sweat, M. S. Terry, and H. M. Conner. 1969. Investigation of staining, polarization, and fluorescence microscopic properties of myoendothelial cells. $J$. Microsc. (Oxf.). 89: 95-104.

6. Wood, J. 1966. Electron microscopic localization of amines in the central nervous system. Nature (Lond.). 209: $1131-1133$

7. Wood, J. G. Cytochemical analytical studies of biogenic amines in ultrathin preparations. In Biological X-Ray Microanalysis by Electron Beam Excitation. C. Lechene and R. Warner, editors. Academic Press, Inc., New York. In press.

8. Conti, G. 1952. L'erection du penis human et ses bases morphologicovasculaires. Acta Anat. 14: 217-262.
9. Burnstock, G. 1972. Purinergic nerves. Pharmacol. Rev. 24: 509-581.

10. Leeson, T. S., and C. R. Leeson. 1965. The fine structure of cavernous tissue in the adult rat penis. Invest. Urol. 3: $144-154$.

11. Thoma, R. 1883. Ueber die Abhangigkeit der Bindegewebsneubildung in der Arterienintima von den Mechanischen Bedingungen des Blutumlaufes. Arch. Pathol. Anat. Physiol. Klin. Med. 93: 443-505.

12. Borst, H., and V. Enderlen. 1909. Die transplantation von Gefassen und ganzen Organin. Dtsch. Z. Chir. 99: 54163.

13. Balis, J. U., M. D. Haust, and R. H. More. 1964. Electron microscopic studies in human atherosclerosis. Exp. Mol. Pathol. 3: 511-525.

14. Reale, E., and H. Ruska. 1965. Die Feinstruktur der Gefasswande. Angiologica (Basel). 2: 314-366.

15. Florey, H. W., S. J. Greer, J. C. F. Poole, and N. T. Werthessen. 1961. The pseudointima lining fabric grafts of the aorta. Br. J. Exp. Pathol. 42: 236-246.

16. Haust, M. D., R. H. More, and H. Z. Movat. 1960. The role of smooth muscle cells in the fibrinogenesis of arteriosclerosis. Am. J. Pathol. 37: 377-389.

17. Ruzbarsky, V., and V. Michal. 1977. Morphologic changes in the arterial bed of the penis with aging. Invest. Urol. 15: $194-199$.

18. Irey, N. S., H. A. McAllister, and J. M. Henry. 1978. Oral contraceptives and stroke in young women: a clinicopathologic correlation. Neurology. 28: 1216-1219.

19. McConnell, J. A., G. S. Benson, and J. Wood. 1979. Autonomic innervation of the mammalian penis: a histochemical and physiological study. J. Neural Transm. 45: 227-238.

20. Burden, H. W., and I. E. Lawrence. 1978. Experimental studies on the acetylcholinesterase-positive nerves in the ovary of the rat. Anat. Rec. 190: 233-242.

21. Baumgarten, H. G., A. F. Holstein, and C. Owman. 1970. Auerbach's plexus of mammals and man: electron microscopic identification of three different types of neuronal processes in myenteric ganglia of the large intestine from rhesus monkeys, guinea-pigs and man. Z. Zellforsch. Mikrosk. Anat. 106: 376-397.

22. Pickel, V. M., D. J. Reis, and S. E. Leeman. 1977. Ultrastructural localization of substance $P$ in neurons of rat spiral cord. Brain Res. 122: 534-540.

23. Pickel, V. M., T. H. Joh, D. J. Reis, S. E. Leeman, and R. J. Miller. Ultrastructural evidence for synaptic interactions between catecholaminergic neurons and axons containing substance $\mathrm{P}$ and (met) ${ }^{5}$-enkephalin. In Proceedings of the Fourth International Catecholamine Symposium. Pergamon Press, Inc., Elmsford, N. Y. In press.

24. Burnstock, G., B. Dumsday, and A. Smythe. 1972. Atropine resistant excitation of the urinary bladder: the possibility of transmission via nerves releasing a purine nucleotide. Br. J. Pharmacol. 44: 451-461.

25. Nilsson, G., and E. Brodin. 1977. Tissue distribution of substance P-like immunoreactivity in dog, cat, rat and mouse. In Substance P. U. S. von Euler and B. Pernow, editors. Raven Press, New York. 49-54.

26. Sundler, F., F. R. Hakanson, L.-I. Larsson, E. Brodin, and G. Nilsson. 1977. Substance $P$ in the gut: an immunochemical and immunohistochemical study of distribution and development. In Substance P. U. S. von Euler and B. Pernow, editors. Raven Press, New York. 59-65.

27. Alm, P., J. Alumets, E. Brodin, R. Hakanson, G. Nilsson, N.-O. Sjoberg, and F. Sundler. 1978. Peptidergic (sub- 
stance P) nerves in the genitourinary tract. Neuroscience. 3: 419-425.

28. Mroz, E. A., and S. E. Leeman. 1977. Substance P. Vitam. Horm. 35: 209-281.

29. Klinge, E., and N. O. Sjöstrand. 1977. Comparative study of some isolated mammalian smooth muscle effectors of penile erection. Acta Physiol. Scand. 100: 354-367.

30. Gilmore, D. P., and J. C. McGrath. 1977. Effects of castration on the mechanical response to motor nerve stimulation of the rat vas deferens. Br. J. Pharmacol. 61: 473474.

31. Raz, S., M. Zeigler, and M. Caine. 1973. The effect of progesterone on the adrenergic receptors of the urethra. Br. J. Urol. 45: 131-135.

32. Schreiter, F., P. Fuchs, and K. Stockamp. 1976. Estrogenic sensitivity of $\alpha$-receptors in the urethra musculature. Urol. Int. 31: 13-19.

33. Hodgson, B. J., S. Dumas, D. R. Bolling, and C. M. Heesch. 1978. Effect of estrogen on sensitivity of rabbit bladder and urethra to phenylephrine. Invest. Urol. 16: 67-69.

34. Weiss, H. D. 1972. The physiology of human penile erection. Ann. Intern. Med. 76: 793-799.

35. Whitelaw, G. P., and R. H. Smithwick. 1951. Some secondary effects of sympathectomy with particular reference to disturbance of sexual function. $N$. Engl. J. Med. 245: 121-130.

36. Root, W. S., and P. Bard. 1947. The mediation of feline erection through sympathetic pathways with some remarks on sexual behavior after deafferentiation of the genitalia. Am. J. Physiol. 151: 80-90. 